\title{
Reduction in blood product transfusion requirements with early on-ECMO repair of congenital diaphragmatic hernia
}

Stephen M. Niemiec ${ }^{1}$, Amanda E. Louiselle1, Ryan Phillips', Sarah A. Hilton'1, Sarkis C. Derderian', Michael V. Zaretsky², Henry L. Galan², Nicholas Behrendt², John P. Kinsella ${ }^{2,3}$, Kenneth W. Liechty ${ }^{1,2}$ and Jason Gien ${ }^{2,3^{*}}$ (1)

\begin{abstract}
Background: For infants with severe congenital diaphragmatic hernia $(\mathrm{CDH})$ stabilized with extracorporeal membrane oxygenation (ECMO), early repair on ECMO improves outcome; however when compared to operative repair after ECMO, repair on ECMO is associated with increase bleeding risk and need for blood product transfusions.

Methods: A retrospective review of 54 patients with $\mathrm{CDH}$ placed on ECMO prior to $\mathrm{CDH}$ repair was performed. For the subset of patients repaired on ECMO, analysis comparing those repaired early (within $48 \mathrm{~h}$ of cannulation) and late (beyond 48 h) on ECMO was performed. Outcomes of interest included survival to discharge, days on ECMO, and postoperative blood product utilization.

Results: When compared to those patients repaired prior to $48 \mathrm{~h}$ of ECMO initiation, $57.7 \%$ of patients survived versus $40.9 \%$ of late repair patients. For those repaired early, blood product utilization was significantly less. Early repair patients received a median of $72 \mathrm{~mL} / \mathrm{kg}$ packed red blood cells (PRBC) and $75 \mathrm{~mL} / \mathrm{kg}$ platelets compared to $151.9 \mathrm{~mL} /$ $\mathrm{kg}$ and $98.7 \mathrm{~mL} / \mathrm{kg}$, respectively ( $p<0.05$ respectively). There was no difference in median days on ECMO $(p=0.38)$.

Conclusion: Our data supports prior reports of improved outcome with repair with $48 \mathrm{~h}$ of ECMO initiation and suggests early repair on ECMO is associated with less bleeding and decreased blood product requirement in the postoperative period.
\end{abstract}

Keywords: Congenital diaphragmatic hernia (CDH), Extracorporeal membrane oxygenation (ECMO), Packed red blood cells, Platelets, Blood transfusion

\section{What is known}

- ECMO use is associated with more severe $\mathrm{CDH}$ and increased risk of morbidity and mortality.

- Patients with $\mathrm{CDH}$ have increased perioperative bleeding when repaired on ECMO.

\section{What is new}

- Early CDH repair after ECMO cannulation is associated with lower perioperative blood product utilization.

- Delaying CDH repair on ECMO in severe patients is not associated with improved outcomes.

\footnotetext{
*Correspondence: Jason.gien@childrenscolorado.org

${ }^{3}$ Department of Pediatrics Section of Neonatology, Children's Hospital

of Colorado, 13123 E. 16th Ave, Aurora, CO 80045, USA

Full list of author information is available at the end of the article
} 


\section{Background}

Congenital diaphragmatic hernia $(\mathrm{CDH})$ is a severe congenital anomaly characterized by pulmonary hypoplasia and pulmonary hypertension due to abdominal visceral herniation into the chest. Up to $40 \%$ of patients born with $\mathrm{CDH}$ fail conventional cardiopulmonary support and are placed on extracorporeal membrane oxygenation (ECMO) for stabilization [1]. Despite advancements in neonatal care, survival among infants placed on ECMO has plateaued around $50 \%$, with a direct correlation between $\mathrm{CDH}$ severity and mortality, where the use of ECMO is both a marker of disease severity and a risk factor for increased morbidity and mortality [2, 3]. ECMO use is associated with increased bleeding risk and mortality $[4,5]$ which is exacerbated when $\mathrm{CDH}$ repair is performed on ECMO.

Where possible, for those patients needing ECMO, repair after ECMO is preferred [5-8]; however for highrisk patients, repair on ECMO is often necessary to minimize the risk of non-repair, allow for compensatory lung growth, and improve the chance of survival $[9,10]$. The optimal timing of $\mathrm{CDH}$ repair on ECMO, whether early or late after cannulation, is yet to be established; however, published reports to date suggest benefit with early repair [6, 9-13]. In a recent study, Dao et al. reported that for centers that perform mostly on ECMO repairs, mortality is improved with early repair on ECMO when compared to repair after weaning from ECMO [11]. While counter to many studies that suggest improvement in survival when repair is delayed until after ECMO decannulation, this report adds to the controversy and debate as to optimal timing of repair for the subset of $\mathrm{CDH}$ patients requiring ECMO. What is clearly outlined in the literature is salvage repair late when patients fail to wean from ECMO is associated with the worst outcomes [911]. This could be secondary to disease severity in these patients, but may also be related to increased complications with late repair on ECMO. Since there is no reliable marker for predicting which patients will quickly wean from ECMO support, based on current reports, early repair on ECMO is recommended; however, ongoing discussions as to optimizing on ECMO repair is important [14].

Not unexpectedly, patients repaired off ECMO have a significantly lower risk of bleeding complications [5]; however, the effect of surgical timing on bleeding risk for patients repaired on ECMO is not established in the literature. Prolonged ECMO runs are associated with increased hemorrhagic and thrombotic events, both from anticoagulation therapy and hemolysis [15], and some studies suggest the ECMO circuitry leads to increased platelet activation and consumption of platelets and coagulation factors [16]. This coagulopathy results in higher transfusion requirements for patients on ECMO [17] and could theoretically increase bleeding risk when patients are repaired on ECMO after a longer duration of cannulation. Therefore, we hypothesized that early repair on ECMO, which we define as within $48 \mathrm{~h}$ of ECMO cannulation, would be associated with decreased transfusion requirements compared to later repair on ECMO and would have better survival outcomes.

\section{Methods}

\section{Patient population and study design}

A retrospective review was performed of all patients with $\mathrm{CDH}$ placed on ECMO and cared for at Children's Hospital Colorado (CHCO) between 2008 and 2020 as approved under institutional review board (COMIRB) protocol number 13-1493. Patients who were placed on ECMO prior to $\mathrm{CDH}$ repair were included in the study. Patient characteristics and outcomes were compared for patients repaired on ECMO and off ECMO. As most patients were repaired on ECMO at our institution, and current recommendations are not standardized on timing of on ECMO repair, analysis of repair timing on outcomes was compared for patients repaired early on ECMO (within $48 \mathrm{~h}$ of ECMO initiation) and those repaired late (beyond $48 \mathrm{~h}$ of ECMO cannulation). Primary outcomes for analysis were survival to discharge, ECMO duration, and blood product utilization in the perioperative period. Blood product usage was defined as packed red blood cell (PRBC), fresh frozen plasma (FFP), platelet, and cryoprecipitate (cryo) volume per kilogram within the first 5 days postoperatively. Secondary outcomes included neonatal survival, bleeding complications, and days of mechanical ventilation. A bleeding complication was defined as a surgical site bleed as documented in the chart or requiring a procedural intervention.

\section{$\mathrm{CDH}$ management and decision for ECMO initiation}

In our institution, care of patients with $\mathrm{CDH}$ utilizes a multidisciplinary team model consisting of neonatologists, pediatric surgeons, maternal fetal medicine specialists, cardiologists, and radiologists. As part of the prenatal evaluation, fetal ultrasound (US) and magnetic resonance imaging (MRI) are performed between 20 and 24 weeks and repeated at 34 weeks gestational age; for the purpose of this study, MRI data from the 34-week gestational age MRI was used for consistency.

At our institution, we have a CDH delivery team, comprised of a neonatal team leader present at all $\mathrm{CDH}$ deliveries, with two additional neonatal attendings, a nurse practitioner, a neonatal nursing team, and an ICU pharmacist. The approach to resuscitation is standardized and involves a coordinated role-based approach to initial stabilization. While one neonatologist intubates, a 
second simultaneously places umbilical lines, an umbilical artery catheter (UAC), and low-lying umbilical vein catheter (UVC), for early assessment of gas exchange and titration of ventilator support. For infants prenatally diagnosed with a percent predicted lung volume (PPLV) $<15 \%$ on MRI, delivery is via scheduled cesarean sections $(\mathrm{C} / \mathrm{S})$. Following intubation, initiation of ventilation, and umbilical line placement, patients are placed on ECMO in the delivery room.

For the remainder of patients, a functional echocardiogram is performed in the delivery room to assess left ventricular (LV) performance and severity of pulmonary hypertension. Patients with moderate or severe LV dysfunction as determined by a pediatric cardiologist are treated with milrinone and low dose epinephrine infusion, while patients with normal LV function are treated with inhaled nitric oxide. Strict gentle ventilation parameters are adhered to during initial stabilization and patients who exceed these parameters are cannulated to ECMO in the delivery room. Additional criteria for ECMO cannulation at our institution are outlined in Table 1. Surgical repair timing for these patients was at the surgeon's discretion.

\section{Anticoagulation and blood product management for patients on ECMO}

Patients are maintained on ECMO with heparin as the primary mode of anticoagulation, using a standardized low bleeding risk heparin titration algorithm and monitoring of anti-Xa levels, targeting a level of $0.2-0.5$. The heparin rate is titrated based on anti-Xa levels collected every $4 \mathrm{~h}$ with rate adjustments of $5-15 \%$ when out of goal range. Coagulation studies are performed every $6 \mathrm{~h}$. Platelets are kept greater than 80,000 with a hematocrit greater than 36 , and coagulation parameters are initially corrected to a prothrombin time $(\mathrm{PT})<18 \mathrm{~s}$ and fibrinogen $>120 \mathrm{mg} / \mathrm{dL}$. All transfusions are given in $10 \mathrm{~mL} / \mathrm{kg}$ aliquots.

The perioperative ECMO anticoagulation algorithm is implemented $4 \mathrm{~h}$ prior to surgery with holding of the heparin, as previously described, and aminocaproic acid (amicar) is given $1 \mathrm{~h}$ prior to incision [16].
Intraoperatively, heparin is held and amicar is infused at $30 \mathrm{mg} / \mathrm{kg} / \mathrm{h}$. Amicar is continued at this rate for 24 $h$ after surgery and restarted if thromboelastography (TEG) suggests clot lysis (lysis $30>4 \%$ ). Anti-coagulation with heparin is restarted at $6 \mathrm{~h}$ after surgery and titrated per high-risk bleeding protocol with goal anti-Xa level of $0.2-0.4$. This is adjusted to a moderate-risk protocol at 24-48 (0.3-0.5) h postoperatively and if no signs active bleeding is transitioned to a low-risk bleeding protocol (0.4-0.7) on postoperative day 2 . The same coagulation parameters described above are followed to guide transfusions; however, TEG is additionally utilized to guide initiation of amicar when clot lysis is suggested by the study. Platelet transfusion is considered for a maximum amplitude (MA) $<48 \mathrm{~mm}$ and cryoprecipitate is considered for a low alpha-angle $<59^{\circ}$, as described previously [19]. Once deemed a low-risk bleeding profile ( $48 \mathrm{~h}$ after surgery with no evidence of bleeding and a stable coagulation profile), fibrinogen, platelet, TEG, prothrombin time, and partial thromboplastin time are followed daily while anti-Xa levels are followed daily and every $4 \mathrm{~h}$ for heparin adjustments.

\section{Statistical analysis}

Non-parametric continuous variables are described as median with interquartile range (IQR) and categorical variables are described as a percentage. Continuous variables were compared using the Mann-Whitney $U$ test while categorical variables were compared using the Fisher's exact test with a two-sided significance level of $\alpha<$ 0.05. Statistical analyses were performed using GraphPad Prism 8 (GraphPad Software, San Diego, CA).

\section{Results}

\section{Patient selection}

As depicted in Fig. 1, 61 patients were placed on ECMO during their hospitalization. Seven patients were excluded from analysis. Four were placed on ECMO during the postoperative period, two underwent fetoscopic endotracheal occlusion (FETO), and one had a severe bronchial anomaly that was found postnatally and placed on hospice. Of the 54 patients analyzed, six were

Table 1 Institutional practices for initiating ECMO cannulation in CDH patients. HFOV high-frequency oscillatory ventilation, SBP systolic blood pressure

Indications for ECMO initiation

Mean airway pressure $>16 \mathrm{cmH}_{2} \mathrm{O}$ and amplitude $>40$ on $\mathrm{HFOV}$ to maintain $\mathrm{pCO}_{2}<60 \mathrm{mmHg}$

Preductal $\mathrm{PaO} 2<40 \mathrm{mmHg}$ (repeated twice, $2 \mathrm{~h}$ apart) [18]

Inability to maintain SBP > $60 \mathrm{mmHg}$ on 3 vasopressors (dopamine $20 \mathrm{mcg} / \mathrm{kg} / \mathrm{min}$, epinephrine $0.5 \mathrm{mg} / \mathrm{kg} / \mathrm{min}$, and vasopression $0.05 \mathrm{units} / \mathrm{kg} / \mathrm{mi}$ )

Inadequate tissue perfusion (refractory metabolic acidosis, rising lactate) 


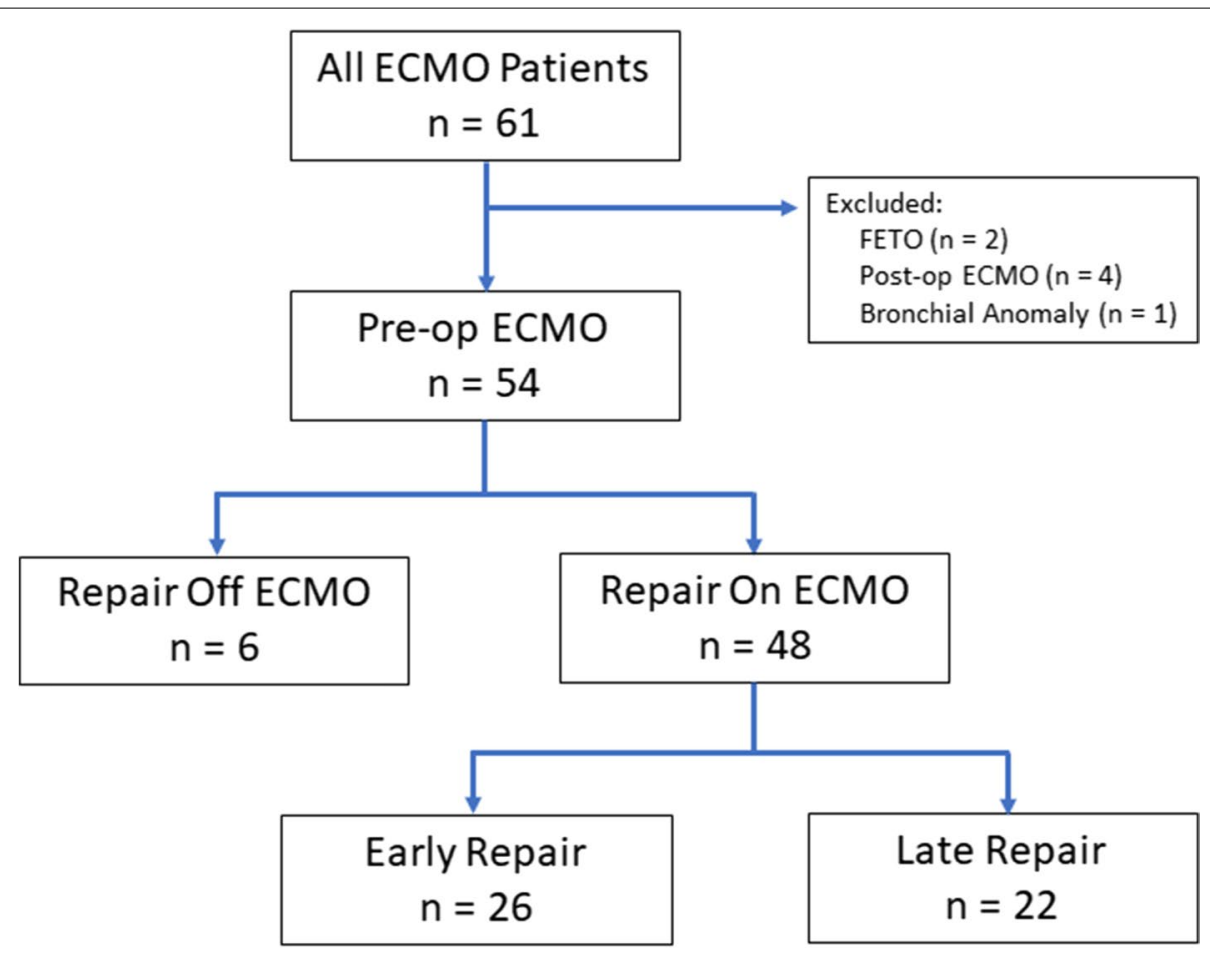

Fig. 1 Patient selection for analysis

repaired off ECMO (off ECMO group). One patient was not repaired after 13 days on ECMO and was included in the "repair on ECMO" group as there was an intention to treat and the non-repair population is important to analyze when discussing survival with delaying repair on ECMO for the goal of first decannulating. Of 48 patients in the on ECMO group, 26 were repaired within $48 \mathrm{~h}$ of ECMO cannulation (early repair) and 22 were repaired beyond $48 \mathrm{~h}$ on ECMO (late repair).

\section{Repair off ECMO versus repair on ECMO}

Patient characteristics between patients who were repaired off ECMO and those repaired on ECMO are compared in Table 2. Patients who were decannulated prior to $\mathrm{CDH}$ repair were repaired later $(p=0.0002)$. Only $33.3 \%$ of patients repaired off ECMO had an intrathoracic liver compared to $95.8 \%$ of patients repaired on ECMO ( $p=0.0007)$. Similarly, off ECMO patients had significantly higher median PPLV on MRI of $21.7 \%$ compared to the on ECMO group of $14.3 \%$ ( $p=0.0131$ ). Post-natal outcomes comparing patients repaired on ECMO to those who were repaired off ECMO are summarized in Table 3. While there was no statistical difference in bleeding complication with this cohort, there was significantly less blood product usage with lower PRBC, FFP, and platelet transfusion requirements in off ECMO repair compared to on ECMO repair $(p<0.0001)$.

\section{Early repair on ECMO versus late repair on ECMO}

A subset analysis of patients repaired early on ECMO and those repaired late on ECMO was performed, with comparison of patient characteristics between these groups shown in Table 4 . The two groups were similar with regard to patient demographics including gestational age, gender at birth, and birth weight; however, a prenatal diagnosis was significantly more common in the early repair group $(p=0.0008)$, which correlated with more cesarean section deliveries in this group $(p=$ $0.0395)$. The majority of patients were cannulated within $24 \mathrm{~h}$ of life, with median day of life 1 for both groups ( $p=$ 0.92). The two groups were similar in all markers of prenatal risk factors including PPLV on MRI and observedto-expected lung-to-head ratio (O/E LHR), presence of an intrathoracic liver, and side of hernia.

A summary of patient outcomes comparing early on ECMO repair to late on ECMO repair is depicted in Table $5.57 .7 \%$ of early repair patients survived to discharge compared to $40.9 \%$ of late repair patients $(p=$ 0.3852 ) and there was additionally no significant difference in duration of ECMO use between the groups. Although there was no statistical difference in the number of patients needing surgical intervention for bleeding, early ECMO repair was associated with significantly lower PRBC and platelet transfusion compared to late repair. Early repair patients received a median of 72.0 
Table 2 Patient characteristics for off ECMO repair v. on ECMO repair. Off ECMO repair patients were less likely to have an intrathoracic liver and had a higher median PPLV than those repaired on ECMO. Data is presented as median (IQR) or as a percentage

\begin{tabular}{|c|c|c|c|}
\hline Variable & Off ECMO repair ${ }^{a}$ & On ECMO repair ${ }^{b}$ & $P$-value \\
\hline Assigned female at birth & $4 / 6(66.7 \%)$ & 23/48 (47.9\%) & 0.6687 \\
\hline Caucasian & 6/6 (100\%) & $31 / 48$ (60.4\%) & 0.1607 \\
\hline Birth weight (kg) & $3.1(2.8-3.4)$ & $3.0(2.5-3.0)$ & 0.3573 \\
\hline Gestational age at birth & $38(37.3-38)$ & $38(37-38)$ & 0.5882 \\
\hline Congenital heart defect & $0 / 6(0 \%)$ & $6 / 48(12.5 \%)$ & $>0.9999$ \\
\hline C-section delivery & $2 / 6(33.3 \%)$ & 28/48 (58.3\%) & 0.3890 \\
\hline 1-min APGAR & $2.5(1-7)$ & $3(1.5-5)(n=35)$ & 0.9036 \\
\hline 5-min APGAR & $6.5(6-8)$ & $5(4.25-7)(n=35)$ & 0.2743 \\
\hline pH at birth & $7.11(7.05-7.11)(n=4)$ & $7.02(6.95-7.14)(n=46)$ & 0.4294 \\
\hline Day of life ECMO started & $1.0(1.0-1.75)$ & $1.0(1.0-1.0)$ & 0.4037 \\
\hline Day of life repaired & $11(8.25-16)$ & $3(2-6)$ & 0.0002 \\
\hline Left-sided hernia & $6 / 6(100 \%)$ & $33 / 48$ (68.8\%) & 0.1702 \\
\hline Intrathoracic liver & $2 / 6(33.3 \%)$ & $46 / 48(95.8 \%)$ & 0.0007 \\
\hline Prenatally diagnosed & $6 / 6(100 \%)$ & 40/48 (83.3\%) & 0.5754 \\
\hline \multicolumn{4}{|l|}{ Prenatal imaging } \\
\hline LHR (US) & $1.3(1.2-1.3)(n=3)$ & $1.0(0.7-1.2)(n=29)$ & 0.0971 \\
\hline O/E LHR (US) & $57.8(57.8-57.8)(n=1)$ & $34.8(23.1-42.4)(n=30)$ & $\mathrm{n} / \mathrm{a}$ \\
\hline TLV (MRI) & $18.4(13.5-26.9)(n=3)$ & $20.3(13.8-42.4)(n=35)$ & 0.9595 \\
\hline PPLV (MRI) & $21.7(20.4-22.9)(n=3)$ & $14.3(12-16.9)(n=34)$ & 0.0131 \\
\hline
\end{tabular}

${ }^{\mathrm{a}} n=6,{ }^{\mathrm{b}} n=48$ unless otherwise noted

Table 3 Patient outcomes with on ECMO versus off ECMO repair. Data is presented as median (IQR) or as a percentage

\begin{tabular}{|c|c|c|c|}
\hline Outcome & Off ECMO repair ${ }^{\mathrm{a}}$ & On ECMO repair ${ }^{b}$ & $P$-value \\
\hline Survival to DC & $5 / 6(83.3 \%)$ & $24 / 48(50 \%)$ & 0.1999 \\
\hline Days on $\mathrm{ECMO}^{\mathrm{C}}$ & $7(6-12)$ & $12.5(8-17.5)$ & 0.0911 \\
\hline 30-day survival & $6 / 6(100 \%)$ & $34 / 48(70.8 \%)$ & 0.3213 \\
\hline $\begin{array}{l}\text { Hospital length of } \\
\text { stay }^{c}\end{array}$ & $53(49-90)$ & $94(72.5-230)$ & 0.0240 \\
\hline Days of MV & $23(14-27)$ & 35 (26.5-139.5) & 0.0163 \\
\hline $\begin{array}{l}\text { Bleeding complica- } \\
\text { tion }\end{array}$ & $0 / 6(0 \%)$ & $21 / 48(43.8 \%)$ & 0.0710 \\
\hline $\begin{array}{l}\text { Perioperative PRBC } \\
(\mathrm{mL} / \mathrm{kg})\end{array}$ & $0(0-59.3)$ & $90.0(60.0-187.8)$ & $<0.0001$ \\
\hline $\begin{array}{l}\text { Perioperative FFP } \\
(\mathrm{mL} / \mathrm{kg})\end{array}$ & $0(0-23.5)$ & $77.1(31.5-140.9)$ & $<0.0001$ \\
\hline $\begin{array}{l}\text { Perioperative Plt } \\
(\mathrm{mL} / \mathrm{kg})\end{array}$ & $0(0-12.9)$ & $84.7(63.1-135.3)$ & $<0.0001$ \\
\hline $\begin{array}{l}\text { Perioperative Cryo } \\
(\mathrm{mL} / \mathrm{kg})\end{array}$ & $0(0-8.4)$ & $0(0-18.6)$ & 0.1223 \\
\hline
\end{tabular}

${ }^{\mathrm{a}} n=6,{ }^{\mathrm{b}} n=48$ unless otherwise noted

c Comparison between patients who survived to discharge

$\mathrm{mL} / \mathrm{kg} \mathrm{PRBC}$ and $75.0 \mathrm{~mL} / \mathrm{kg}$ platelets while late repair patients received a median $151.9 \mathrm{~mL} / \mathrm{kg}$ and $98.7 \mathrm{~mL} /$ $\mathrm{kg}$, respectively. Secondary outcomes of length of stay and days of mechanical ventilation were no different between the two groups; however, the early repair group had trends towards less days on mechanical ventilation (median of 33 days (IQR 23-69 days) versus 56 days (IQR 31-201 days) and shorter length of stay (median of 93.5 days (IQR 68.8-161.3 days) versus 125 days (IQR 78-259 days). Finally, early repair had significantly higher neonatal period survival at $84.6 \%$ compared to $54.5 \%$ of late repair patients $(0.0294)$.

\section{Discussion}

We found that among patients who were repaired on ECMO, early repair within $48 \mathrm{~h}$ of cannulation was associated with significantly lower blood product utilization in the postoperative period, specifically with reduced transfusion of platelets and PRBCs. One possible reason for this reduction in blood product usage is the significant coagulopathy associated with longer ECMO duration, such as platelet consumption and hemolysis [15, 16]. This is consistent with our data presented in Table 3 showing that our patients who were repaired after ECMO decannulation had significantly lower perioperative transfusion requirements, with the majority requiring no postoperative transfusions.

Although there were only six patients at our institution who were repaired after ECMO decannulation, it is important to note that they had trends toward improved survival with $83 \%$ survival to discharge compared to $50 \%$ of patients who underwent on ECMO repair. The 
Table 4 Patient characteristics comparing early on ECMO repair versus late on ECMO repair. The two groups had similar prenatal risk factors, but the early repair group was more likely to be prenatally diagnosed and have earlier ECMO cannulation. Data is presented as median (IQR) or as a percentage

\begin{tabular}{llll}
\hline Variable & Early repair $^{\mathbf{a}}$ & Late repair $^{\mathbf{b}}$ & $\boldsymbol{P}_{\text {-value }}$ \\
\hline Assigned female at birth & $11 / 26(42.3 \%)$ & $12 / 22(54.5 \%)$ & 0.5627 \\
Caucasian & $19 / 26(73.1 \%)$ & $12 / 22(54.5 \%)$ & 0.2323 \\
Birth weight $(\mathrm{kg})$ & $3.0(2.5-3.0)$ & $2.9(2.4-3.1)$ & 0.9380 \\
Gestational age at birth & $38(37-38)$ & $38(37.5-38.5)$ & 0.0605 \\
Congenital heart defect & $3 / 26(11.5 \%)$ & $3 / 22(13.6 \%)$ & $>0.9999$ \\
C-section delivery & $19 / 26(73.1 \%)$ & $9 / 22(40.1 \%)$ & $\mathbf{0 . 0 3 9 5}$ \\
1-min APGAR & $4(2-6)$ & $3(1-5)$ & 0.4218 \\
5-min APGAR & $7(5-8)$ & $5(4-6.8)$ & 0.0610 \\
pH at birth & $7.02(6.95-7.09)(n=25)$ & $7.01(6.9-7.19)$ & 0.7623 \\
Day of life ECMO started & $1.0(1.0-1.0)$ & $1.0(1.0-1.0)$ & 0.9203 \\
Day of life repaired & $2(2-2.75)$ & $7(5-9)$ & $<\mathbf{0 . 0 0 0 1}$ \\
Left-sided hernia & $17 / 26(65.4 \%)$ & $16 / 22(72.7 \%)$ & 0.7563 \\
Intrathoracic liver & $25 / 26(96.2 \%)$ & $21 / 22(95.5 \%)$ & $>0.9999$ \\
Prenatally diagnosed & $26 / 26(100 \%)$ & $14 / 22(63.6 \%)$ & $\mathbf{0 . 0 0 0 8}$ \\
Prenatal imaging & $1.05(0.68-1.23)(\mathrm{n}=20)$ & & \\
$\quad$ LHR (US) & $34.9(27.5-42.4)(\mathrm{n}=22)$ & $0.89(0.73-1.09)(\mathrm{n}=10)$ & \\
O/E LHR (US) & $19.0(12.8-24.5)$ & $24.5(20-42.7)(\mathrm{n}=9)$ & \\
TLV (MRI) & $13.5(11-16.7)(n=25)$ & $23(16-26.6)(\mathrm{n}=9)$ & 0.7865 \\
PPLV (MRI) & & $15(14-19)(\mathrm{n}=9)$ & 0.2970 \\
\hline
\end{tabular}

${ }^{\mathrm{a}} n=26,{ }^{\mathrm{b}} n=22$ unless otherwise noted

Table 5 Patient outcomes with early on ECMO repair versus late on ECMO repair

\begin{tabular}{|c|c|c|c|}
\hline Outcome & Early repair ${ }^{a}$ & Late repair ${ }^{b}$ & $P$-value \\
\hline Survival to DC & $15 / 26(57.7 \%)$ & 9/22 (40.9\%) & 0.3852 \\
\hline Days on $\mathrm{ECMO}^{\mathrm{c}}$ & $12(8-15)$ & $14(10-18)$ & 0.3847 \\
\hline 30-day survival & $22 / 26(84.6 \%)$ & $12 / 22(54.5 \%)$ & 0.0294 \\
\hline Hospital length of stay ${ }^{c}$ & $93.5(68.8-161.3)$ & $125(78-259)$ & 0.5674 \\
\hline Days of MV & $33(23-69)$ & $56(31-201)$ & 0.1507 \\
\hline Bleeding complication & 9/26 (34.6\%) & $12 / 22(54.5 \%)$ & 0.2439 \\
\hline $\begin{array}{l}\text { Perioperative PRBC } \\
(\mathrm{mL} / \mathrm{kg})\end{array}$ & $72.0(49.8-91.4)$ & $151.9(94.4-248.4)$ & 0.0015 \\
\hline $\begin{array}{l}\text { Perioperative FFP (mL/ } \\
\mathrm{kg})\end{array}$ & $79.3(34.1-126.3)$ & $76.8(31.4-203.3)$ & 0.4662 \\
\hline Perioperative Plt (mL/kg) & $75.0(61.7-87.6)$ & $98.7(72.3-174.7)$ & 0.0486 \\
\hline $\begin{array}{l}\text { Perioperative Cryo (mL/ } \\
\text { kg) }\end{array}$ & $0(0-9.7)$ & $6.7(0-32.2)$ & 0.1761 \\
\hline
\end{tabular}

Data is presented as median (IQR) or as a percentage

${ }^{\mathrm{a}} n=26,{ }^{\mathrm{b}} n=22$ unless otherwise noted

c Comparison between patients who survived to discharge

patients who were repaired off ECMO also tended to have a shorter ECMO duration, with median duration of 7 days compared to 12.5 days for those repaired on ECMO. This is likely secondary to severity of illness as antenatal predictors were more favorable in this group; however, other factors such as outborn versus inborn may have contributed. To date, there is unfortunately not a predictive model for determining which patients will successfully wean from ECMO prior to repair. We found in our review that patients repaired off ECMO had significantly higher median PPLV on MRI and were more likely to have an intra-abdominal liver, which could highlight some important predictors for patients who may be good candidates to attempt to wean from ECMO prior to repair rather than undergo an early repair on ECMO. In our report, patients with an O/E LHR $<35 \%$ tended to be repaired on ECMO which when combined with intrathoracic liver position may serve as a marker for who should be repaired on ECMO. Defining the optimal candidate for repair on ECMO is yet to be elucidated; however, when considering repair on ECMO, current evidence as well as our data suggest benefit with early over late repair.

For patients who undergo surgical repair while on ECMO, early repair could not only reduce ECMOassociated bleeding risk at the time of repair but could theoretically permit earlier compensatory lung growth while resting on ECMO, although outcomes have been mixed $[6,11-13]$. Robertson et al. found that survival was not significantly different between those repaired before and after 5 days following cannulation at $43.3 \%$ and $41.2 \%$, respectively [6]. Dassinger et al., meanwhile, 
showed a survival of over $70 \%$ in those repaired on ECMO after a mean duration of cannulation of $55 \mathrm{~h}$ with significantly lower bleeding complications compared to registry data where mean timing of repair was just under 7 days [12]. Early repair on ECMO could potentially lower overall duration of ECMO use as well; our data showed a trend toward lower median duration of ECMO at 12 days in the early repair group compared to 14 days in the late repair group. These patients also trended toward lower duration of mechanical ventilation and shorter lengths of hospitalization, which could have major clinical significance, but will require further investigation with larger data sets to confirm these trends.

Although statistical significance was limited by power, similar to previously published reports, we see a $16.8 \%$ greater survival to discharge (57.7\% compared to $40.9 \%$ ) in the early on ECMO repair group, which had similar prenatal risk factors for $\mathrm{CDH}$ severity as the late on ECMO repair group. Despite this, there was a higher neonatal survival in the early on ECMO repair group, which may be secondary to decreased surgical risk and less ECMO-related platelet consumption and hemolysis when compared to the late on ECMO repair group, as up to $18 \%$ of mortality following CDH repair on ECMO can be attributed to post-surgical bleeding [5]. 34.6\% of the early repair group had a bleeding complication requiring surgical intervention compared to $54.5 \%$ in the late repair group, which while not statistically significant, is clinically very significant and was associated with significant differences in PRBC and platelet transfusion requirements. Cryoprecipitate use was low for all patients, with the majority of patients not receiving cryoprecipitate postoperatively regardless of grouping. Median FFP transfusion requirement was similar for both the early and late repair groups, which was a surprising finding in our study. We would have expected increased utilization of all blood products, but it is possible that increased platelet consumption is the greater contributor to bleeding risk in the late repair group, and further investigation of the effect of prolonged ECMO duration on clotting factors may be beneficial in guiding optimal product utilization. Indications for FFP transfusion at our institution is a PT $>24 \mathrm{~s}$ and if it is greater than $24 \mathrm{~s}$ for three consecutive tests will start a continuous FFP infusion at $10 \mathrm{~mL} / \mathrm{kg} / \mathrm{h}$. At our institution, patients who were repaired off ECMO received a median $15.66 \mathrm{~mL} / \mathrm{kg}$ FFP per day on ECMO, which is similar to the $16.21 \mathrm{~mL} / \mathrm{kg}$ FFP per day seen in those repaired on ECMO. This suggests that baseline FFP transfusion requirements are high while patients are on ECMO, and therefore, we may not see a significant increase at the time of surgery without a larger sample size.
Early repair on ECMO may not only reduce bleeding risk associated with $\mathrm{CDH}$ repair, but by lowering transfusion requirements it could reduce both cost and transfusion risks. We did not see any transfusion-related complications in our cohort of patients; however, higher transfusion requirements increase the potential for complications such as infection, transfusion-related acute lung injury (TRALI), and febrile non-hemolytic transfusion-related reactions $[18,20]$.

As a single-institutional study, there is a limit to its generalizability across institutions, as our described protocols may differ from other programs. Most of our patients who undergo ECMO cannulation preoperatively are repaired on ECMO, so a critical evaluation of our on-ECMO outcomes is important but limited by the retrospective nature of the review. Clinical implications of repair timing on long-term survival and ECMO usage will require ongoing prospective evaluation and multiinstitutional study. Our data suggests that for patients who undergo early repair on ECMO, there is a reduction in PRBC and platelet transfusion requirements with improvements in neonatal survival. To our knowledge, this is the first study to evaluate the association of surgical timing on ECMO with perioperative blood product usage, which could have implications for more effective resource utilization.

\section{Abbreviations \\ $\mathrm{CDH}$ : Congenital diaphragmatic hernia; ECMO: Extracorporeal membrane oxygenation; PRBC: Packed red blood cells; FFP: Fresh frozen plasma; cryo: Cryoprecipitate; US: Fetal ultrasound; MRI: Magnetic resonance imaging; UAC : Umbilical artery catheter; UVC: Umbilical venous catheter; LV: Left ventricular; PT: Prothrombin time; PPLV: Percent predicted lung volume; TRALI: Transfu- sion-related acute lung injury; FETO: Fetoscopic endotracheal occlusion; O/E LHR: Observed-to-expected lung-to-head ratio.}

\section{Acknowledgements}

None

Authors' contributions

All authors contributed to the study conception and design. Data collection and analysis were performed by Stephen Niemiec, Amanda Louiselle, Ryan Philips, and Sarah Hilton. The first draft of the manuscript was written by Stephen Niemiec and all authors commented on previous versions of the manuscript. All authors read and approved the final manuscript.

Funding

No funding was received for conducting this study.

Availability of data and materials

All data generated or analyzed during this study are included in this published article

\section{Declarations}

Ethics approval and consent to participate

This manuscript does not contain any studies with human or animal participants. The study was approved by institutional review board and ethics committee. Data was collected and analyzed anonymously in accordance with privacy legislation. Waiver of consent was granted. 


\section{Consent for publication}

N/A.

\section{Competing interests}

The authors of this manuscript have no relevant financial or non-financial interests to disclose.

\section{Author details}

'Laboratory for Fetal and Regenerative Biology, Department of Surgery, University of Colorado Denver School of Medicine and Children's Hospital Colorado, 1775 Aurora CT, Aurora, CO 80045, USA. ${ }^{2}$ Colorado Fetal Care Center, Colorado Institute for Fetal \& Maternal Health, Children's Hospital of Colorado, 13123 E. 16th Ave, Aurora, CO 80045, USA. ${ }^{3}$ Department of Pediatrics Section of Neonatology, Children's Hospital of Colorado, 13123 E. 16th Ave, Aurora, CO 80045, USA.

Received: 19 August 2021 Accepted: 22 October 2021

Published online: 03 January 2022

\section{References}

1. Logan JW, Rice HE, Goldberg RN, Cotten CM. Congenital diaphragmatic hernia: a systematic review and summary of best-evidence practice strategies. J Perinatol. 2007;27(9):535-49. https://doi.org/10.1038/ sj.jp.7211794.

2. Saugstad OD. When increased mortality indicates improved care: $\mathrm{CDH}$ ECMO registry data. J Pediatr. 2017;190:4-5. https://doi.org/10.1016/j. jpeds.2017.09.037.

3. Turek JW, Nellis JR, Sherwood BG, Kotagal M, Mesher AL, Thiagarajan $\mathrm{RR}$, et al. Shifting risks and conflicting outcomes-ECMO for neonates with congenital diaphragmatic hernia in the modern era. J Pediatr. 2017;190:163-8.e4. https://doi.org/10.1016/j.jpeds.2017.08.010.

4. Desai AA, Ostlie DJ, Juang D. Optimal timing of congenital diaphragmatic hernia repair in infants on extracorporeal membrane oxygenation. Semin Pediatr Surg. 2015;24(1):17-9. https://doi.org/10.1053/j.sempedsurg.2014. 11.004 .

5. Golden J, Jones N, Zagory J, Castle S, Bliss D. Outcomes of congenital diaphragmatic hernia repair on extracorporeal life support. Pediatr Surg Int. 2017;33(2):125-31. https://doi.org/10.1007/s00383-016-4002-2.

6. Robertson JO, Criss CN, Hsieh LB, Matsuko N, Gish JS, Mon RA, et al. Comparison of early versus delayed strategies for repair of congenital diaphragmatic hernia on extracorporeal membrane oxygenation. J Pediatr Surg. 2018;53(4):629-34. https://doi.org/10.1016/j.jpedsurg.2017.10.056

7. Bryner BS, West BT, Hirschl RB, Drongowski RA, Lally KP, Lally P, et al. Congenital diaphragmatic hernia requiring extracorporeal membrane oxygenation: does timing of repair matter? J Pediatr Surg. 2009;44(6):1 16571; discussion 71-2. https://doi.org/10.1016/j.jpedsurg.2009.02.022.

8. Delaplain PT, Harting MT, Jancelewicz T, Zhang L, Yu PT, Di Nardo M, et al. Potential survival benefit with repair of congenital diaphragmatic hernia $(\mathrm{CDH})$ after extracorporeal membrane oxygenation (ECMO) in select patients: Study by ELSO CDH Interest Group. J Pediatr Surg. 2019;54(6):1132-7. https://doi.org/10.1016/j.jpedsurg.2019.02.052.
9. Partridge EA, Peranteau WH, Rintoul NE, Herkert LM, Flake AW, Adzick NS, et al. Timing of repair of congenital diaphragmatic hernia in patients supported by extracorporeal membrane oxygenation (ECMO). J Pediatr Surg. 2015;50(2):260-2. https://doi.org/10.1016/j.jpedsurg.2014.11.013 Epub 2014 Nov 7.

10. Fallon SC, Cass DL, Olutoye OO, Zamora IJ, Lazar DA, Larimer EL, et al. Repair of congenital diaphragmatic hernias on extracorporeal membrane oxygenation (ECMO): does early repair improve patient survival? J Pediatr Surg. 2013;48(6):1172-6. https://doi.org/10.1016/j.jpedsurg.2013.03.008.

11. Dao DT, Burgos CM, Harting MT, Lally KP, Lally PA, Nguyen HT, et al. Surgical repair of congenital diaphragmatic hernia after extracorporeal membrane oxygenation cannulation: early repair improves survival. Ann Surg. 2019. https://doi.org/10.1097/SLA.0000000000003386.

12. Dassinger MS, Copeland DR, Gossett J, Little DC, Jackson RJ, Smith SD, et al. Early repair of congenital diaphragmatic hernia on extracorporeal membrane oxygenation. J Pediatr Surg. 2010;45(4):693-7. https://doi.org/ 10.1016/j.jpedsurg.2009.08.011.

13. Steen EH, Lee TC, Vogel AM, Fallon SC, Fernandes CJ, Style CC, et al. Congenital diaphragmatic hernia repair in patients on extracorporeal membrane oxygenation: how early can we repair? J Pediatr Surg. 2019;54(1):50-4. https://doi.org/10.1016/j.jpedsurg.2018.10.038.

14. Kays DW. ECMO in CDH: Is there a role? Semin Pediatr Surg. 2017;26(3):166-70. https://doi.org/10.1053/j.sempedsurg.2017.04.006

15. Dalton HJ, Garcia-Filion P, Holubkov R, Moler FW, Shanley T, Heidemann S, et al. Association of bleeding and thrombosis with outcome in extracorporeal life support. Pediatr Crit Care Med. 2015;16(2):167-74. https://doi. org/10.1097/PCC.00000000000000317.

16. Muntean W. Coagulation and anticoagulation in extracorporeal membrane oxygenation. Artif Organs. 1999;23(11):979-83. https://doi.org/10. 1046/j.1525-1594.1999.06451.x.

17. Henriquez-Henriquez M, Kattan J, Chang M, Pizarro I, Faunes M, Martinez C, et al. Blood component usage during extracorporeal membrane oxygenation: experience in 98 patients at a Latin-American tertiary hospital. Int J Artif Organs. 2014;37(3):233-40. https://doi.org/10.5301/ijao.50003 11.

18. Chang TT. Transfusion therapy in critically ill children. Pediatr Neonatol. 2008;49(2):5-12. https://doi.org/10.1016/S1875-9572(08)60004-2.

19. Phillips RC, Shahi N, Leopold D, Levek C, Shirek G, Hilton S, et al. Thromboelastography-guided management of coagulopathy in neonates with congenital diaphragmatic hernia supported by extracorporeal membrane oxygenation. Pediatr Surg Int. 2020;36(9):1027-33. https://doi. org/10.1007/s00383-020-04694-0.

20. Zhou JJ, Hemphill C, Walker CT, Farber SH, Uribe JS. Adverse effects of perioperative blood transfusion in spine surgery. World Neurosurg. 2021;149:73-9. https://doi.org/10.1016/j.wneu.2021.01.093.

\section{Publisher's Note}

Springer Nature remains neutral with regard to jurisdictional claims in published maps and institutional affiliations.

\section{Submit your manuscript to a SpringerOpen ${ }^{\odot}$ journal and benefit from:}

- Convenient online submission

- Rigorous peer review

- Open access: articles freely available online

- High visibility within the field

- Retaining the copyright to your article

Submit your next manuscript at $\boldsymbol{\nabla}$ springeropen.com 